Research Article

\title{
Crescents in renal biopsies and crescentic glomerulonephritis - A 5 year study from South India
}

\author{
Ravikumar G. ${ }^{1}$, Rout P. ${ }^{2}$ \\ ${ }^{1}$ Dr. Gayatri Ravikumar, Assistant Professor, Dr. Pritilata Rout, Professor and Head, both are affiliated with Department \\ of Pathology, St. John's Medical College, Sarjapur Road, Koranmangala, Bangalore, India.
}

Address for Correspondence: Dr. Gayatri Ravikumar, Assistant Professor, Department of Pathology, St.John's Medical College. E-mail: gayatri.ravikumar@gmail.com

\begin{abstract}
Background: Crescents indicate active disease with rapidly deteriorating renal function. Many primary renal diseases can be associated with crescents, however only a few conditions presents as crescentic glomerulonephritis (CrGN). The incidence varies in different population. Aims and objective: The aim of the study was to know the incidence of CrGN and that of crescents in various glomerulopathies along with their clinicopathological associations. Material and methods: Renal core biopsies over 5 year period were collected retrospectively from pathology archives and reviewed for crescents and CrGN. Clinical, serological, Immunoflourescence and follow up details were collected. Results: A total of 1629 renal biopsies were received. Crescents were identified in $9.69 \%$ and $2.08 \%$ were CrGN. Males and females were equally distributed. Paediatric population constituted $24 \%$. The most common presentation was nephritic syndrome. Cellular crescents were seen in 81 cases, fibro cellular/ fibrous in 55 cases and both in 22 cases. In immune complex(IC) mediated group, lupus nephritis (LN) showed crescents in 31.7\%, followed by PIGN (29.67\%) and IgAN (25.2\%). Vasculitis group had 79\% crescents. All cases of anti GBM disease and pauci immune ANCA negative renal limited vasculitis (PI-RLV) had crescents. The most common CrGNs were anti GBM disease (100\%), followed by vasculitis (37\%) and PI-RLV (33\%) and least in IC group (5\% in PIGN and IgAN and 3.5\% in LN). Complete remission was seen in 32.2\%. Conclusion: Crescents in renal biopsies are not rare. Although CrGN is more common in vasculitis and antiGBM disease, the incidence of IC-GN is more in our population and a significant number may show crescents.
\end{abstract}

Key words: Crescents, Crescentic glomerulonephritis, immune complex mediated, pauci-immune ANCA negative vasculitis.

\section{Introduction}

Crescents in renal biopsy indicate an active disease. It is the most common biopsy diagnosis which clinically presents as rapidly progressive renal failure. Many of the glomerulonephritides harbour crescents. Crescentic glomerulonephritis ( $\mathrm{CrGN}$ ) is diagnosed only when more than fifty per cent of the glomeruli show crescents and can be broadly grouped into three categories:

Immune-complex mediated glomerulonephritis, pauciimmune glomerulonephritis and anti-glomerular basement membrane (GBM) disease [1]. Crescents indicate damage to the glomerular basement membrane with extravasation of inflammatory mediators into the

Manuscript received: $27^{\text {th }}$ April 2017

Reviewed: $7^{\text {th }}$ May 2017

Author Corrected: $16^{\text {th }}$ May 2017

Accepted for Publication: $24^{\text {th }}$ May 2017
Bowman's space [2], which leads to proliferation of the parietal epithelium. It is not a disease entity by itself and is a histopathological representation of acute glomerular injury. CrGN is a well-studied entity, however the clinicopathological spectrum of the glomerular disease associated with crescents in renal biopsies has not been presented in detail in the literature from India, with sparse data from South India.

With the awareness that population based differences in the disease patterns are known to exist, it is useful to have studies on different population groups to know the incidence and behaviour of the disease entity to tailor population specific treatment. This study was therefore undertaken to know the incidence of crescents and CrGN in the population served by our centre and to 
categorise the cause of crescents with the help of immuno-fluorescence and serology. The clinicopathological correlation and follow up wherever available was also studied.

\section{Material and Methods}

Study design: This was a retrospective observational descriptive study.

Setting and data source: Renal biopsies received for routine histopathological diagnosis were retrospectively collected from the archives of the Department of Pathology, St.John's Medical College, Bangalore. They were classified into various groups based on immunohistological criteria and are listed in Table1.

Table1: Classification of renal core biopsies based on immunohistological features.

\begin{tabular}{|l|}
\hline I. Immune complex mediated \\
\hline a. Lupus nephritis (LN) \\
\hline b. IgA nephropathy (IgAN), \\
\hline c. Post infectious glomerulonephritis (PIGN) \\
\hline d. Membranoproliferative glomerulonephritis (MPGN) \\
\hline e. Membranous glomerulopathy (MGN), \\
\hline f. Thrombotic microangiopathy (TMA), \\
\hline g. Henoch Schonlein purpura nephritis (HSP-N) \\
\hline II. Vasculitis group \\
\hline III. Anti-GBM disease \\
\hline IV. Pauci-immune ANCA negative renal limited vasculitis \\
\hline
\end{tabular}

Inclusion and exclusion criteria: All the renal core biopsies over a 5 year period were included. Renal biopsies in cases of accelerated hypertension (HT) and diabetic nephropathy (DN) were also included. In cases where there was no definite histopathological diagnosis /descriptive/ inconclusive diagnosis the biopsies were grouped under no definite diagnosis (NDD). Renal core biopsies done for non-glomerular disease and transplant renal biopsies were recorded separately to get total numbers. There were no definite exclusion criteria.

Variables: The histopathology reports of these biopsies were reviewed and those with crescents were recorded. Amongst these cases, those which had more than $50 \%$ crescents were classified as CrGN. The clinical investigations considered include proteinuria, hematuria, presence of hypertension and increasing serum creatinine levels. Urine protein creatinine ratio (PCR) and serum complement levels were also recorded and categorised as normal, increased or decreased. Immunoflourescence and serological findings (ANA, ANCA and dsDNA) were also noted. Follow up details were collected and classified into various categories as listed in Table 2. Patients who had relapse and patients who had undergone renal transplant were also recorded. The study has been approved by the Institutional ethics committee (IEC ref no. 106/2014).

Table-2: Classification of follow up details of the patients.

\begin{tabular}{|c|c|}
\hline Follow up & Parameter for classification \\
\hline Complete remission & $\begin{array}{c}\text { Proteinuria }<0.33 \mathrm{~g} / \mathrm{dl} \text { and } \\
\text { Serum creatinine }<1.4 \mathrm{mg} / \mathrm{dl}\end{array}$ \\
\hline Partial remission & $\begin{array}{c}\text { GFR }<60 \mathrm{ml} / \mathrm{min} / 1.73 \mathrm{~m}^{2} \text { for }>3 \mathrm{months} \\
\end{array}$ \\
\hline Chronic kidney disease & Patients required dialysis for maintenance of renal function \\
\hline Dialysis dependant & $\begin{array}{c}\text { When renal replacement therapy was considered (when GFR is } \\
\left.<10 \mathrm{ml} / \mathrm{min} / 1.73 \mathrm{~m}^{2}\right) \text { or When there was worsening renal function }\end{array}$ \\
\hline Poor prognosis & GFR is $<15 \mathrm{ml} / \mathrm{min} / 1.73 \mathrm{~m}^{2}$ \\
\hline End stage renal disease & \\
\hline
\end{tabular}

Statistical analysis: The study being descriptive in nature, frequencies were calculated and no other statistical methods were employed. 


\section{Results}

Characterisation of the cases: There were a total of 1629 renal core biopsies received over a five year period, excluding the repeat biopsies, therefore assuring true prevalence of the glomerular pathology. Crescents were identified in 158 patients $(9.69 \%)$, of which 34 (2.08\%) were classified as CrGN. Of the 158 patients, $38(24 \%)$ were in the paediatric age group, i.e. age up to 18 years and the rest were adults $(76 \%)$. There was a near equal distribution of male and female patients (78 and 80 respectively). The most common clinical presentation was nephritic syndrome and some patients were known cases of lupus nephritis (LN), thrombotic microangiopathy (TMA) etc. Table 3 summarises the various clinical presentations in this group of patients.

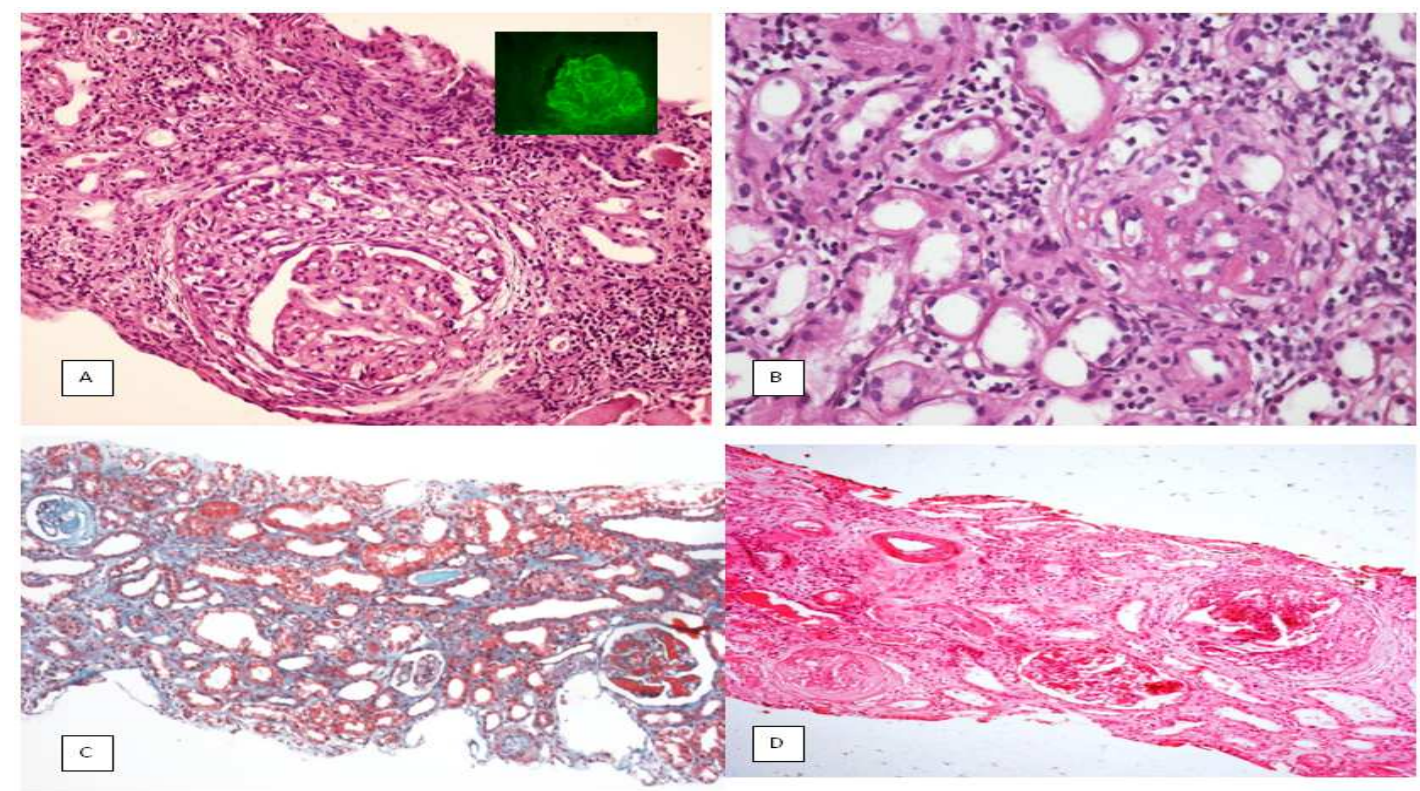

Figure-1(A-D): Photomicrographs showing crescents in A-Membranous nephropathy (H \& E stain, original magnification, 20X), inset showing IgG positivity on immunoflourescence. B- HSP nephritis (H and E, original magnification, 40X). C- Thrombotic microangiopathy (Masson's trichrome stain, original magnification, 10X). DDiabetic nephropathy (H\&E stain, original magnification, 10X).

Table-3: Clinical Presentation of patients with crescents in renal biopsy.

\begin{tabular}{|c|c|}
\hline Clinical presentation & Percentage of cases \\
\hline Nephritic Syndrome & 31.21 \\
\hline Rapidly worsening renal failure & 28.02 \\
\hline Lupus nephritis & 15.28 \\
\hline Nephritic Nephrotic syndrome & 3.18 \\
\hline Nephrotic syndrome & 2.54 \\
\hline Atypical Nephrotic syndrome & 2.54 \\
\hline Hematuria & 3.18 \\
\hline Edema & 1.91 \\
\hline Acute interstitial Nephritis(AIN) & 0.6 \\
\hline Acute interstitial Nephritis(AIN)+HIV & 0.6 \\
\hline Thrombotic microangiopathy & 0.6 \\
\hline
\end{tabular}

The relevant biochemical investigations and serological findings are listed in Table 4. Hypertension was present in $72 \%$ of cases. 
Table-4: Biochemical and serological investigations in patients with crescents.

\begin{tabular}{|c|c|}
\hline Investigations & Percentage of cases \\
\hline Proteinuria & 99.21 \\
\hline Hematuria & 82.94 \\
\hline Increasing creatinine & 91.45 \\
\hline Higher urine PCR $(\mathrm{n}=67)$ & 100 \\
\hline Decreased complement levels $(\mathrm{n}=85)$ & 56.5 \\
\hline ANA positivity $(\mathrm{n}=123)$ & 27.6 \\
\hline ANCA positivity $(\mathrm{n}=64)$ & 14 \\
\hline ds DNA positivity $(\mathrm{n}=42)$ & 57 \\
\hline
\end{tabular}

Histopathological findings: The mean number of glomeruli was 12 (range 4-40). Cellular crescents were seen in 81 cases, fibro-cellular and fibrous crescents in 55 cases and 22 cases had both cellular and fibrous crescents. Segmental fibrinoid necrosis of the glomerular tufts was noted in 31 cases. Changes in the tubules were not significant other than casts and varying grades of tubular atrophy. An occasional case showed acute tubulointersitial nephritis. The interstitium showed periglomerular and perivascular granulomata in 2 cases of vasculitis and the rest had non- significant findings. Fibrinoid necrosis of the arterioles in the interstitium was seen in $9.49 \%$ cases.

The distribution of cases amongst the various histopathological diagnoses along with those showing crescents and CrGN are detailed in Table 5. The most common cause of crescents in the immune-complex (IC) mediated group was lupus nephritis, which showed crescents in $31.7 \%$ cases. The other common IC GNs with crescents were post-infectious glomerulonephritis (PIGN) (29.67\%) followed by IgA nephropathy (25.2\%). CrGN was relatively more common in the latter two than lupus nephritis. In the vasculitis group, 19 were ANCA related, of which 15 showed crescents and 7 were CrGN. There were 6 cases of pauci-immune ANCA negative renal limited vasculitis all of which showed crescents and 2 were CrGN. Anti-GBM disease was $100 \% \mathrm{CrGN}$. The rare findings in the present study include: a patient who was positive for ANCA and ANA and showed CrGN and 2 other patients who had connective tissue disorders other than lupus and both showed crescents with one being CrGN. Also there was one case each of Membranous nephropathy, thrombotic microangiopathy and diabetic nephropathy with crescents.

Table-5: Distribution of cases with crescents among renal biopsies for glomerular pathology and the total number in 5 years.

\begin{tabular}{|c|c|c|c|}
\hline Histopathological diagnosis & $\begin{array}{c}\text { Total number of cases } \\
\text { (5 years) }\end{array}$ & $\begin{array}{c}\text { Numbers with crescents } \\
\text { including CrGN (\%) }\end{array}$ & No. of CrGN $\{\%\}$ \\
\hline Lupus Nephritis & 142 & $45(31.7)$ & $5(3.5)$ \\
\hline IgAN & 115 & $29(25.2)$ & $6(5.21)$ \\
\hline PIGN & 91 & $27(29.7)$ & $5(5.5)$ \\
\hline MPGN & 54 & $8(14.8)$ & $1(1.9)$ \\
\hline $\begin{array}{c}\text { Vasculitis } \\
\text { (ANCA mediated ) }\end{array}$ & 19 & $15(79)$ & $7(37)$ \\
\hline $\begin{array}{c}\text { Pauciimmune ANCA } \\
\text { negative, renal limited) }\end{array}$ & 6 & $6(100)$ & $2(33)$ \\
\hline Accelerated HT & 35 & $4(11.4)$ & - \\
\hline $\mathrm{MN}$ & 122 & $1(0.8)$ & - \\
\hline Anti GBM & 4 & $4(100)$ & $4(100)$ \\
\hline TMA & 6 & $1(16.7)$ & - \\
\hline HSP & 20 & $3(15)$ & $1(5)$ \\
\hline $\mathrm{DN}$ & & 1 & - \\
\hline No definite diagnosis & 11 & $1(9)$ & $1(9)$ \\
\hline
\end{tabular}


Research Article

Follow up: Follow up details were available in $62.1 \%$ cases with a mean follow up period of 14 months. The patients received either one or a combination of the following treatment regimens based on clinical decision: pulse methylprednisolone, endoxan (cyclophosphamide) or wysolone. Some patients required dialysis and some had plasmapheresis. Complete and partial remission was seen in $32.2 \%$ and $2 \%$ cases respectively. In $11.39 \%$ there was chronic kidney disease and 6.96\% required renal replacement therapy or had worsening renal failure. Five percent of patients were dialysis dependent. Relapse, post transplant status and ESRD was seen in $1.2 \%$ patients each.

\section{Discussion}

Crescents in renal biopsy are a result of insult to the glomerular capillary tufts due to the inflammatory mediators. As a result of the inflammatory insult, the parietal epithelial cells start proliferating and form crescents within the Bowman's space. The extent of crescent formation is an indicator of the disease severity. In the early stages crescents are cellular and progress to fibro-cellular crescents with passage of time. Finally the cellular crescents are replaced by collagen and lead to fibrous crescents which lead to a non-functioning glomerulus [3].

Crescents can be seen in the different forms of glomerulonephritis which can be broadly classified into three groups: immune-complex mediated glomerulonephritis, vasculitis and anti-GBM antibody disease [4]. Amongst the immune-complex mediated glomerulonephritis the most common ones associated with crescent formation are lupus nephritis, postinfectious GN, IgAN and membrano-proliferative glomerulonephritis.The recognition of crescents in renal biopsy is often associated with rapidly worsening renal function and rapidly progressive glomerulonephritis (RPGN) was the most commonly used terminology for any clinical condition with worsening renal failure.

Crescentic glomerulonephritis ( $\mathrm{CrGN})$ is diagnosed when more than $50 \%$ of the glomeruli show crescents. According to Steen Oslen, CrGN might constitute a final common pathway for several glomerular diseases which are severe etiologically and pathogenetically [5].

Although crescents can be diagnosed on light microscopy with utmost certainty, it is insufficient to know the underlying cause without the aid of immunoflourescence and serology, with addition of electron microscopy wherever available. The rapid and accurate diagnosis of $\mathrm{CrGN}$ is essential to initiate appropriate therapy for optimal patient outcome. Among the three broad categories of glomerulonephritis with crescents, $\mathrm{CrGN}$ is more common in pauciimmune ANCA mediated glomerulonephritis and antiGBM disease than in immune complex mediated GN.
The incidence of crescents in renal biopsies in the present study is $9.69 \%$ and that of $\mathrm{CrGN}$ is $2.08 \%$. In a 2 year study of CrGN from North Indian, Gupta et al reported an incidence of $2.65 \%$, which is similar to the present study. Unlike our study, the highest incidence of CrGN $(71.7 \%)$ was in the pauci-immune group, followed by IC-GN $(28.3 \%)$ [6], whereas we found a higher incidence in the IC mediated group. Reports from China have also shown a higher incidence of CrGN among the IC group, constituting $68.6 \%$ of CrGN, followed by pauci-immune group with an incidence of $22.7 \%$, similar to the present study. They also had $8.7 \%$ of $\mathrm{CrGN}$ related to anti-GBM disease whereas this did not feature in the study by Gupta et al. [6,7]. The incidence of CrGN varies across the world with studies from Western Europe and North America reporting an incidence of 2-10\% and studies from South Africa reporting $3.8 \%$ [8-11]. The IC CrGN is more common in young adults, whereas vasculitis related CrGN is common in elderly and anti-GBM is uncommon in any age. The paediatric cases constituted $24 \%$ of total renal biopsies with crescents and $20.58 \%$ of CrGN.

Choudhury et al reported an incidence of $\mathrm{CrGN}$ in 5.5\% of their cases in a 3.5 year study from North India. They had predominantly adult patients with only $11.7 \%$ in the age group below 20 years [12]. Gupta et al had $26.08 \%$ $\mathrm{CrGN}$ in the paediatric group, but their age definition of paediatric was much younger (less than 14 years)[6]. Among the paediatric CrGN, the most common cause is IC GN as per evidence from the literature [13-15], whereas Sinha et al reported an equal incidence of both pauci-immune and IC CrGN in children, in their study on 36 children, under 18years, with CrGN from North India [16].

CrGN usually presents as rapidly worsening renal failure [7] which was the second most common presentation followed by nephritic symptoms in this study. CrGN is more common in anti-GBM disease followed by pauci-immune GN than ICGN as seen in the present study. Jennette and Thomson have reported 
Research Article

a similar finding in their study on 6000 native kidney biopsies [2]. The incidence of crescents and $\mathrm{CrGN}$ in their study is similar to the present study but for a minor differences within the IC GN group. LN showed a higher incidence of $\mathrm{CrGN}$ amongst the IC group, in both the studies and in the present study PIGN was slightly higher and there were fewer number of HSP compared to Jennette et al report [2]. The difference in percentage was marginal and it could probably represent a population based difference in the incidence of these ICGNs. Overall the percentage of CrGN was much lower in ICGN group indicating that ICGN is not as severe a form of GN compared to anti-GBM or pauci-immune group of GNs. As the study included all the renal biopsies with crescents and not exclusively CrGN, nearly half the cases had complete remission on follow up.

\section{Conclusion}

In conclusion, crescents in renal biopsies are not a rare occurrence and $\mathrm{CrGN}$ has an incidence of $2.08 \%$ of all renal biopsies. Although $\mathrm{CrGN}$ is more common in vasculitis and anti-GBM disease, the incidence of ICGN is more in our population and a significant number of them may show crescents. They progress rapidly and warrant urgent notification to the clinician. They are managed aggressively with steroids and cytotoxic agents and in patients who fail to respond to medical management the option of renal replacement therapy and transplant are considered.

Conflict of Interest statement: On behalf of both the authors, the corresponding author states that there is no conflict of interest, Funding: Nil,

Permission from IRB: Yes

\section{References}

1. Jennette JC. Crescentic glomerulonephritis.In: Jennette JC,Olson JL,Schwartz MM, Silva FG,eds. Heptinstall's Pathology of the Kidney, $5^{\text {th }}$ edn, Chapter 14. Lippincott-Raven,Philadelphia,1998;625-56.

2. Jennette JC, Thomas DB. Crescentic glomerulonephritis. Nephrol Dial Transplant.2001; 16(suppl 6):80-82 DOI: http://dx.doi.org/10. 1093/ ndt/16. suppl_6.80

3. Mathieson PW. The ins and outs of glomerular crescent formation. Clin Exp Immunol. 1997 Nov;110 (2):155-7.
4. Jennette JC, Nickeleit V. Anti Glomerular Basement Membrane Glomeruloephritis and Goodpasture's syndrome. In: Jennette JC,Olsen JL, Schwartz MM, Silva FG,editors.Heptinstall's Pathology of the kidney. $6^{\text {th }}$ ed. Philadelphia: Lippincott Williams \& Wilkins; 2007.p. 613- 641.

5. Osler S. Extracapillary glomerulonephritis: A semiquantitative light microscopical study of 59 patients.Acta Pathol Microbiol Scand[A] 1974;Suppl 249:7.

6. Gupta R, Singh L, Sharma A, Bagga A, Agarwal SK, Dinda AK. Crescentic glomerulonephritis: A clinical and histomorphological analysis of 46 cases. Ind J Pathol Micro .2011; 54(3): $497-500$ DOI: http://dx.doi.org/10.4103/0377-4929.85081

7. Tang Z, Wu Y, Wang Q, Zeng C, Yao X, Hu W, Chen H, Liu Z, Li L. Clinical spectrum of diffuse crescentic glomerulonephritis in Chinese patients. Chin Med J (Engl). 2003 Nov;116(11):1737-40.

8. Jennette JC, Falk RJ. Antineutrophil Cytoplasmic autoantibodies and associated diseases: A review. Am J Kid Dis 1990;15(6):517-25. DOI: http://dx.doi.org/10. 1016/ S0272-6386(12)80521-X.

9. Andrassy K, Kuster S, Waldherr R, Ritz E. Rapidly progressive glomerulonephritis, analysis of prevalence and clinical course. Nephron 1991; 59(2):206-12. DOI: http://dx.doi.org/10.1159/000186552.

10. Zent R, Van Zyl Smit R, Duffield M, Cassidy MJ. Crescentic Glomerulonephritis at Goote Shuur Hospital, South Africa, not a benign disease. Clin Nephrol 1994; 42(1):22-9.

11. Pettersson EE, Sundelin B, Heigl Z. Incidence and outcome of pauci-immune necrotizing and crescentic glomerulonephritis in adults. Clin Nephrol. 1995 Mar; 43(3):141-9.

12. Choudhury TA, Singh RG; Usha, Singh S, Singh TB, Rathore SS; Prabhakar. Clinicopathologic spectrum of crescentic glomerulonephritis: a hospital-based study. Saudi J Kidney Dis Transpl. 2014 May;25(3): 689-96.

13. Jardim HM, Leake J, Risdon RA, Barratt TM, Dillon MJ. Crescentic glomerulonephritis in children. Pediatr Nephrol. 1992 May;6(3):231-5. 
14. Srivastava RN, Moudgil A, Bagga A, Vasudev AS, Bhuyan UN, Sunderam KR. Crescentic glomerulonephritis in children: a review of 43 cases. Am J Nephrol. 1992; 12(3):155-61.DOI: http://dx.doi.org/ 10. 1159/000168438.

15. Dewan D, Gulati S, Sharma RK, Prasad N, Jain M, Gupta A, et al. Clinical spectrum and outcome of crescentic glomerulonephritis in children in developing countries. Pediatr Nephrol. 2008;23(3):389-94. DOI: http://dx.doi.org/10.1007/s00467-007-0647-3.

16. Sinha A,Puri K, Hari P, Dinda A K,Bagga A. Etiology and outcome of crescentic glomerulonephritis. Indian Pediatrics.2013;50(3):283-288DOI: http://dx.doi. org/10.1007/s13312-013-0095-z.

\section{How to cite this article?}

Ravikumar G, Rout P. Crescents in renal biopsies and crescentic glomerulonephritis- A 5 year study from South India. Trop J Path Micro 2017;3(2):174-180.doi: 10.17511/jopm.2017.i2.18. 